\title{
Entre vida real e criação: a correspondência como reservatório da ficção
}

\author{
Between real life and creation: the correspondence as a reservoir of fiction
}

Marie-Hélène Paret Passos

Pontifícia Universidade Católica do Rio Grande do Sul - Porto Alegre - Rio Grande do Sul - Brasil

$\diamond$

\begin{abstract}
Resumo: A pesquisa em acervos de escritores pode revelar-se uma fonte profícua de informações, para a análise de uma produção literária, por serem verdadeiros reservatórios memoriais que guardam rastros processuais e testemunhos de vida. Geralmente, a correspondência que os escritores mantiveram durante a vida está conservada nesses arquivos e, quando consultada, ela pode fornecer ao pesquisador informações fundamentais, não somente sobre um momento preciso da vida do escritor mas também sobre suas práticas de escritura e a gênese de algumas obras. Mostraremos como, uma carta encontrada no arquivo Caio Fernando Abreu, possibilitou uma outra leitura do conto "Uma estória confusa".
\end{abstract}

Palavras-chave: Caio Fernando Abreu; Correspondência; Gênese; Processo de criação

\begin{abstract}
The research in writers' collections can be a useful source of information for the analysis of a literary production for they are real reservoirs of memory that keep procedural traces and life testimonies. Usually, the correspondence that the writer maintained during his life is conserved in theses archives and, when are consulted, they can supply the researcher fundamental information not only concerning one moment of the writer's life but also on his practices of writing and the genesis of some literary works. We will show as a letter found in the archive Caio Fernando Abreu made possible a different reading of the short story "Uma estória confusa".
\end{abstract}

Keywords: Caio Fernando Abreu; Correspondence; Genesis; Creative process

No acervo Caio Fernando Abre ${ }^{1}$, que se encontra sob curadoria do DELFOS ${ }^{2}$ (Espaço de documentação e Memória Cultural) na PUCRS (http://www.pucrs.br/ delfos/), um total de 2782 itens compõem o catálogo acessível em linha, compostos de manuscritos, correspondência, fotografias, LP, fitas cassetes, runas, tarôs e outros objetos.

Os acervos de escritores são reservatórios memoriais por guardarem testemunhos de vida, tanto pessoais quanto literários, registrados em vários tipos de suportes materiais ou virtuais, geralmente constituídos por centenas de documentos heteróclitos que pertencem à esfera privada do escritor e que aparentemente não dizem respeito ao público leitor. Parte desse material, a que

\footnotetext{
1 Doravante: Caio F.

2 Localizado no $7^{\circ}$ andar da Biblioteca Central Irmão José Otão da PUCRS.
}

concerne aos "papéis", constitui-se em objeto de estudo da crítica genética, e, uma vez organizada, classificada e analisada, essa massa documental pode fornecer pistas interpretativas da obra analisada pelo pesquisador. Dentro desses diversos papéis, está, entre outros, a correspondência.

No campo dos estudos literários é patente o valor do estudo da correspondência dos escritores. Para a Crítica Literária, é um recurso fundamental no que concerne a pesquisas de fontes ou biográficas. No campo da Crítica Genética, cuja vocação é o estudo do processo criativo, embora, na maioria das vezes e dependendo de suas características, a carta não seja considerada como documento genético propriamente dito, é incontestável que ela pode trazer informações primordiais posto que tem um papel de testemunha e que, cedo ou tarde, poder-se-á encontrar seu conteúdo, ou parte dele, reciclado no texto de uma obra literária. Quando acontece, é um fato que 
pode modificar de forma radical, não somente a análise da obra em questão mas também a leitura dessa mesma obra. Veremos que a leitura do conto aqui apresentado, "Uma estória confusa", não é idêntica em função de conhecer ou não a sua gênese.

Em minha pesquisa no acervo Caio Fernando Abreu (CFA) encontrei duas versões ${ }^{3}$ do conto, uma datilografada (datiloscrito) e outra impressa a partir do computador (digitoscrito), assim como um recorte de jornal Zero Hora, de 06/10/1974, da primeira versão publicada e uma carta a Vera Antoun ${ }^{4}$, na qual se alude ao conto mencionado. Somente os dois primeiros documentos referidos são documentos genéticos, manuscritos de trabalho, pois guardam os rastros de uma escritura em processo e situam-se antes da fase da publicação.

\section{Função da correspondência}

Sabe-se que a função primeira de uma carta é a comunicação, portanto, é motivada por um destinatário e escrita em função desse destinatário preciso que pode ter uma influência sobre quem a escreve. Assim, Caio F., na carta a Vera Antoun, escrita em Porto Alegre, em 05/10/19745, que aqui me ocupa, o escritor, indeciso, pede à amiga sua opinião a respeito do título de uma peça. Após enumerar vários títulos, ele indaga: "qual você gosta mais?", mais adiante, após ter contado um acontecimento peculiar que gerou expectativa nesse momento de sua vida, ele ainda, pergunta: "você acha que a pessoa vai aparecer?".

Desse modo, a escritura epistolar não é um discurso biográfico como pode ser o do diário. É uma forma de comunicação específica, diferente, sendo o destinatário ausente, muitas vezes longe, inalcançável. Nesse sentido, a carta vem paliar a falta da comunicação presencial. Com redação desencadeada pela distância, geralmente geográfica mas nem sempre, ela pode alcançar altos graus de proximidade, e intimidade, como é o caso da correspondência de Caio F. que, ao longo da vida, se revelou um dos mais prolixos missivistas brasileiros. Um fato que, para os diversos biógrafos do escritor, tornou a passagem por essa correspondência uma etapa praticamente obrigatória para ter acesso a testemunhos fidedignos de estados de espírito, de sentimentos e emoções profundos, e a informações pertinentes sobre o surgimento e a criação de certas obras.

Escrever cartas de forma compulsiva talvez tenha sido, para Caio F., uma forma de conjurar o profundo sentimento de solidão que raramente o deixava, "ti espero em carta", escrevia a Vera Antoun. Durante a escritura da carta, compartilha-se um momento de intensa proximidade com o destinatário, uma forma de preencher o vazio da solidão, sentimento e sensação que, ciclicamente, assolavam o íntimo do escritor, o levando a escrever ainda e sempre.

Por outro lado, Caio F. foi grande leitor de correspondência, a de Clarice Lispector ou Camille Claudel, das quais costumava emprestar frases.

Em seu artigo "Qual genética para as correspondências”, José-Luiz Dias (2007) aponta a carta como arquivo da literatura: "O caso em que a carta do escritor testemunha a gênese de uma obra literária - da qual ela funciona como laboratório ou simplesmente como caixa registradora - é o mais clássico, o mais conhecido, o mais seguro". Na carta já mencionada, Caio F. comunica uma informação de primeira mão, lemos o trecho:

\begin{abstract}
Amanhã é domingo e sai um conto meu num suplemento. Duas semanas atrás recebi uma carta anônima: uma carta maravilhosa, duma pessoa que sabe mil coisas a meu respeito. Mas anônima. Aí escrevi um conto sobre, incluindo um trecho da carta e pedindo enfim, para a pessoa revelar-se (é a segunda carta que ela me escreve em dois anos - sei só que nasceu a 22 de setembro de 1954, às 4 horas da tarde). Chama-se "Uma estória confusa".
\end{abstract}

O conto, "Uma estória confusa", foi publicado pela primeira vez em 06/10/1074 na Revista ZH, suplemento cultural do jornal Zero Hora e posteriormente na coletânea de contos Ovelhas negras, em $1995^{6}$.

\section{Cartas em acervos: uma fonte de informações}

Graças à presença da carta no acervo e à possibilidade de acessá-la, obtive uma informação primordial sobre a gênese do conto. Foi a partir de uma situação vivenciada pelo escritor: a recepção de uma carta anônima, que surgiu a ideia de "escrever sobre". Trata-se de uma informação factual e pontual, contentando-se em mencionar uma situação da vida real que deu origem a uma criação ficcional na qual um trecho do próprio texto da carta anônima recebida foi incorporado. Vemos, então, como é tênue essa fronteira entre o real e o ficcional, e como é facilmente transgredida, e até abolida, nesse caso. Ao ler o conto impresso é impossível saber que a matéria da carta ficcional é a própria matéria da carta real, portanto, o acesso ao arquivo, e à carta, abriu uma outra possibilidade de leitura analítica do conto. Agora, é

\footnotetext{
3 A versão é um estado já relativamente acabado de uma elaboração textual. Documentos acessíveis pela referência: CFA CLI 0805.

4 Vera Antoun, grande amiga carioca que o escritor conheceu em 1970, quando morava no Rio de Janeiro, na ocasião do lançamento de seu primeiro romance Limite Branco.

5 Referência do documento: CFA COR 0091. Vera Antoun doou ao DELFOS um total de 40 cartas que Caio F. lhe escreveu.

6 Recebeu o Prêmio Jabuti em 1996.
} 
com um olhar diferente que abordamos o texto, levando em conta o caráter autobiográfico que impulsionou o processo escritural, pode-se enveredar, entre outros, para uma abordagem autoficcional do conto. Ítalo Moriconi, o primeiro a publicar parte da correspondência de Caio F., escreveu (2002, p. 15):

Na medida em que o trabalho de Caio era escrever, as cartas fazem parte do mesmo movimento produtivo de que brotam suas crônicas, suas ficções, suas peças teatrais, suas resenhas e matérias jornalísticas, assim como presumivelmente seu diário, ainda não revelado ao público. Tudo produto de um mesmo processo de vida se fazendo na escrita, enunciação e enunciado condicionando-se mutuamente, escrita alimentandose de vida, vida transcendida pelo simbólico, metáfora que universaliza.

Na primeira versão do conto em 1974, o alimento escritural é literalmente um fato da vida que nutre o movimento criativo e redunda em uma estrutura narrativa de extrema imbricação, o que confere à tessitura textual uma densidade podendo levar à confusão das personagens, recurso recorrente na escritura de Caio $\mathrm{F}$. quando a intensão é tornar obscuro, procurando intensificar o efeito da leitura para amplificar emoção e perplexidade. $\mathrm{O}$ próprio título já anuncia a situação. Por outro lado, a não nomeação das personagens é também um recurso criativo do escritor que remete a um processo de ficcionalização da realidade, nomes reais mascaram-se atrás de pronomes pessoais que se emaranham, tornando tênues os limites corporais das personagens. No conto, o desdobramento de uma única individualidade entre um ele personagem e um eu-narrador, é um recurso ficcional para, a partir de um pseudo- diálogo intratextual, estabelecer um diálogo extratextual.

De certa forma o próprio conto funciona como uma tribuna, ou carta pública, na qual o escritor responde ao missivista anônimo pedindo que se identifique e se manifeste. Então, pela informação dada por Caio F. a Vera Antoun, é possível apreender o conto como uma forma de dupla mise en abyme ${ }^{7}$. De fato, são duas as cartas: a carta real dentro da carta ficcional e a carta ficcional dentro, e como, carta real. Por outro lado, e fora do conto, são também duas as cartas: a escrita e enviada por Caio F. a Vera Antoun, e que pode ser consultada no acervo, e a recebida por Caio F., a anônima, que não pode ser consultada, pois não se encontra no acervo -

\footnotetext{
7 Denominação oriunda de um procedimento heráldico. Noção introduzida por André Gide na crítica literária a partir de 1891. Designa o fenómeno de reprodução de um escudo por uma peça situada no seu centro. Diz-se que uma figura está em abyme quando ocupa, com outras figuras, o meio do escudo sem tocar nenhuma dessas figuras (minha tradução). (DÄLLENBACH,1997, p. 17)

8 É um documento exterior ao dossiê de arquivos. (DIAZ, 2007, p. 125).
}

estando provavelmente em posse de alguém. Aqui, talvez seja possível dizer que, paradoxalmente, a carta ausente, por natureza "exogenética" fragmentado de trabalho por ter um trecho inserido nos dois manuscritos encontrados nos acervos e detectáveis graças à confissão de Caio F. à amiga Vera Antoun.

Por outro lado, o recurso à mise en abyme permite burlar as fronteiras do real e da ficção, fazendo da criação literária um meio para expressar e transcender uma intensa expectativa, e proporciona uma via de comunicação pessoal, quase um código secreto, com o desconhecido correspondente. Entre os milhares de leitores anônimos do conto no jornal, está, certamente, o leitor-missivista-anônimo.

No conto, a personagem "ele" recebe uma carta anônima; está nervoso pois não é a primeira, ele não lê a carta cuja leitura é feita pelo eu-narrador. No manuscrito da primeira versão o trecho epistolar está entre aspas e sublinhado a lápis

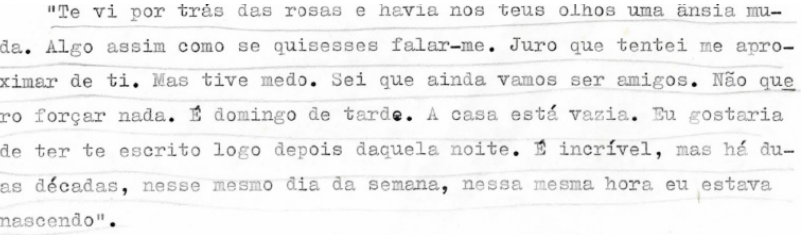

No recorte de jornal, o trecho está entre aspas e no digitoscrito e no livro Ovelhas negras aparece em itálico.

Pela carta a Vera Antoun em que Caio F. escreve: "inclui[ndo] um trecho da carta", é possível deduzir que este é o trecho da carta anônima. Na sequência, instaurase um diálogo entre a personagem "ele" e o eu-narrador acerca da identidade do correspondente desconhecido, em que a personagem revela ter descoberto, com o auxílio de uma tabela astrológica, que ele ("Tenho quase certeza que é um rapaz", diz a personagem) nasceu em 22 de setembro de 1954, às quatro da tarde, sob o signo da virgem. Lembremos que Caio F. escreve a Vera Antoun: "sei só que nasceu a 22 de setembro de 1954, às 4 horas da tarde". No decorrer do diálogo a personagem confessa: "Tenho escrito para ele" e o eu-narrador pergunta: "O que você diz nessas cartas?". A resposta é dada em dois tempos, primeiro de forma indireta: "Eu peço socorro. Eu digo que às vezes tenho vontade de ter um amigo novo [...]"; em seguida, de forma direta

Eu digo assim: "Chegue bem perto de mim. Me olhe, me toque, me diga qualquer coisa ou não diga nada. Não seja idiota, não deixe isso se perder, virar poeira, virar nada. Daqui há [sic] pouco já não vou estar mais aqui. Daqui há $[s i c]$ pouco vai crescer e achar graça de tudo isso. Antes que isso aconteça, por favor, chegue perto". 
Em sua carta a Vera Antoun, Caio F. diz ter pedido, no conto, para o correspondente revelar-se, o que motiva a pergunta à amiga, citada p. 1: "você acha que a pessoa vai aparecer?".

Contudo, embora traga informações pertinentes, se a carta não guarda os rastros do processo criativo, ela fornece dados cronológicos fundamentais e informações da esfera privada e íntima. Ela pertence a uma zona temporal definida e caracteriza, aqui, o segmento genético "pós gênese", segundo tipologia estabelecida por de Biasi (2007), pois concerne à obra editada, quando o escritor comenta sua obra. Pela carta de Caio F., sabemos que o conto foi escrito duas semanas antes de sua publicação, quando ele recebeu a carta anônima: "duas semanas atrás recebi uma carta anônima". Essa informação temporal, embora pouco precisa, permite definir uma proximidade entre a recepção da carta e o início do processo de escritura: não somente a carta desencadeou a escritura do conto mas está presente nela.

Duas semanas antes, ou quatorze dias, situa, então, a recepção da carta anônima e o provável início da escritura, o que remete, segundo o calendário de 1974, ao dia 21 de setembro, um sábado. Portanto, é possível deduzir que o tempo escritural do conto situa-se entre os dias 21 de setembro e 5 de outubro de 1974. No entanto, Caio F. escreve na carta: "amanhã é domingo e sai um conto meu num suplemento". De fato, no recorte de jornal consta a data de 06/10/1974, então pode-se supor que a versão para impressão foi enviada para o jornal com, pelo menos, alguns dias de antecedência, o que reduz o tempo de escritura. É uma informação relevante para a análise do conto, quer a partir do manuscrito, quer a partir do texto publicado. De fato, o texto, impactante e conciso, é uma lufada, derrama um magma de emoção, um desesperado apelo, é repleto de reticências, imbuído do momento vivido, da esperança de um novo amigo, ou novo amor, na ansiedade e na efusão da proximidade da recepção da carta. Parece não haver distanciamento entre vida e criação, sobretudo na última parte do conto, cujo estilo lembra muito o fluxo de consciência, entrelaçando pensamentos espontâneos, reflexão profunda, estado de espírito, caraterísticos da prosa de Caio F.

Em relação ao segundo trecho citado entre aspas, não seria equivocado pensar que provem também da carta anônima. Contudo, em manuscritos de contos anteriores a 1974, essa frase: "daqui a pouco eu já não vou mais estar aqui" é uma ideia já presente no texto de Caio F., por outro lado, na sua carta Caio F. menciona que incluiu "um trecho da carta" anônima. Portanto é possível deduzir que o trecho emprestado do anonimato se limita ao primeiro. No entanto, como diz Pierre-Marc de Biasi (2007) não podemos esquecer que a carta é um meio de comunicação, fortemente marcada pelo destinatário, pelas circunstâncias e pela motivação, o objetivo da carta está fora dos conteúdos da mensagem. É nesse sentido que devemos desconfiar, pois uma carta pode conter mentiras em torno de algumas verdades. Tudo o que está dito a alguém está dito num caso preciso, numa intensão precisa, diferente do manuscrito, quando e escritor está em situação de trabalho e de comunicação com si-próprio.

De fato, a partir do salientado por de Biasi, constatamos que não é possível confirmar as referências cronológicas dadas por Caio F. - que acrescenta entre parênteses: (é a segunda carta que ela me escreve em dois anos). Como saber se a ideia do conto não estava adormecida desde então e só veio à tona com essa segunda missiva anônima? Somente é possível concluir que é temerário tentar circunscrever o início de um processo criativo mental. A partir das informações temporais da carta pode-se, somente, reconstituir o tempo material do processo de escritura que deixou rastros nas duas versões manuscritas e redundou em uma primeira publicação no suplemento literário. No entanto, as aspas circunscrevem o texto que a personagem, em carta, escreve para o correspondente anônimo e não deixa de assumir um papel de mensagem, velada para quem não leu a carta de Caio F., e patente para quem a conhece.

Se o tempo de escritura da primeira versão publicada foi imbuído da realidade de vida e se deu num provável prazo de uma dezena de dias, pode-se dizer que a revisão do texto para sua publicação em Ovelhas negras, 21 anos depois, apresenta características diferentes, praticamente opostas. Pois, 21 anos depois, a primazia é literária, o processo criativo retoma seus direitos e afasta o que foi, outrora, um sentimento devastador que invadiu a criação. Um cotejo das duas versões, genéticas ou publicadas, permitirá estabelecer um levantamento das modificações decorrendo da reescritura e, a partir desse trabalho, embasar uma nova análise. No entanto, a presente reflexão não enfoca esse estudo detalhado, contudo, de forma panorâmica, é possível dizer que a segunda versão apresenta uma escritura literária com ritmo mais lento, controlado pelo escritor aguerrido, à procura do distanciamento. As substituições de palavras tendem para a precisão, a estrutura do conto é construída para acrescentar informações sobre o correspondente anônimo. Por outro lado, é patente a construção da personagem "ele", que ganha uma esposa, Martha, mas continua pedindo socorro para o desconhecido, queixando-se do casamento fracassado. De forma geral, é possível dizer que, pelo tempo passado desde a primeira versão, o resgate 
memorial do antigo fato possibilitou uma reescritura livre da emoção do instante desencadeada pela recepção inesperada da carta anônima. Na pequena introdução (ABREU, 2002, p. 198) que, no livro, antecede o conto, lemos

Uma primeira versão desta história foi publicada em 1974, na Revista ZH, de Zero Hora, e escrita provavelmente no mesmo ano, em Porto Alegre. Esta versão, a definitiva, foi totalmente reescrita. Creio que ganhou, embora pareça paradoxal, mais ambiguidade e mais clareza.

A presença do provavelmente confirma que o tempo levou embora o impacto da carta anônima, do desejo, da esperança de um novo encontro, e, de certa forma, libertou o escritor da insustentável leveza das tênues fronteiras do vivido e do sonhado.

\section{Referências}

ABREU, Caio Fernando. Ovelhas negras. Porto Alegre: L\&PM, 2002.

BIASI, Pierre-Marc de. 2007. Analyse de la correspondance et genèse de l'oeuvre: le cas Flaubert. Disponível em: <http:// www.diffusion.ens.fr/index.php?res $=$ conf\&idconf $=1646>$. Acesso em: 26 jan. 2014.

BIASI, Pierre-Marc de. A genética dos textos. Tradução MarieHélène Paret Passos. Porto Alegre: EDIPUCRS, 2010.

DÄLLENBACH, Lucien. Le récit spéculaire. Paris: Seuil, 1977.

DIAZ, José-Luiz. Qual genética para as correspondências? Tradução de Cláudio Hiro e Maria Silva Ianni Barsalini. In: Manuscritica, n. 15, p. 119-162.

MORICONI, Ítalo. Caio Fernando Abreu. Cartas. Rio de Janeiro: Aeroplano, 2002.

Recebido: 10 de março de 2014

Aprovado: 25 de março de 2014

Contato: marie-helene.passos@acad.pucrs.br 